\title{
The mechanism of intraocular pressure rise after keratoplasty
}

Diana Wyroślak-Bednarek, Zofia Pniakowska, Piotr Jurowski

Department of Ophthalmology and Vision Rehabilitation,

Medical University of Lodz

Head: Prof. Piotr Jurowski, MD, PhD

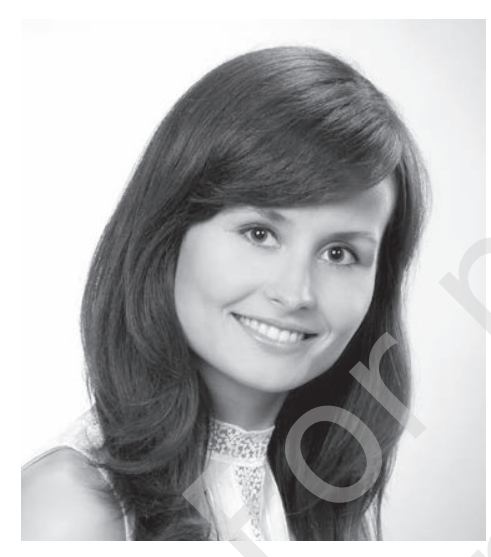

\section{ABSTRACT}

Purpose: To determine the pathomechanism of increased intraocular pressure

H I G H L I G H T S

Iridocorneal angle assessment using standard methods as well as spectroscopic AS-OCT is crucial to diagnose morphometrical changes potentially leading to increased intraocular pressure after keratoplasty. after penetrating and lamellar keratoplasty based on clinical observation and literature data.

Materials and methods: Morphometric analysis of the anterior segment of the eye using spectroscopic optical coherence tomography, gonioscopy and biomicroscopy.

Results: Pre- and postoperative spectroscopic optical coherence tomography scans in patients after keratoplasty reveal deformation of the peripheral cornea, narrowing of the iridocorneal angle, presence of anterior synechiae and various types of pupillary block.

Conclusions: The mechanism of elevated intraocular pressure after corneal grafting is complex and depends on pre-, intra- and postoperative factors, such as anatomy changes of the iridocorneal angle, presence of anterior synechiae as well as anterior and posterior pupillary block. Spectroscopic optical coherence tomography plays an important role in diagnosis and further treatment management.

Key words: keratoplasty, keratoplasty postoperative complications, secondary glaucoma 


\section{INTRODUCTION}

Nowadays, keratoplasty is a well known ophthalmic surgery and the most common procedure in transplantology. It dates back to 1905, when dr Eduard Zirm performed the first successful penetrating keratoplasty (PKP) in patient with corneal lime burns [1]. In Poland number of performed keratoplasties is comparable with total number of all other transplantations [2]. Popularity of keratoplasty is based on its high efficacy consisting of immune privilege of cornea and anterior chamber as well as improvement in surgical techniques and tissue storage procedures. Nevertheless, keratoplasty bears a risk of postoperative complications, such as increased intraocular pressure (IOP) and glaucoma. Uncontrolled elevated IOP not only decreases eye function and graft survival but can also lead to blindness. The risk of transplant rejection is almost 3 times higher in patients with preoperative glaucoma than in patients without glaucoma [3].

Increased IOP after keratoplasty was described in 1969 for the first time [4]. Nowadays, it is observed after penetrating [5-10] as well as lamellar keratoplasty [11-13] and its frequency oscillates around 27-36\%. Elevated IOP depends on pre-, intra- and postoperative factors. Among preoperative factors glaucoma plays a main role and can increase the risk of elevated IOP after Descemet's stripping endothelial keratoplasty (DSEK) by 10\% [11]. Intraoperative factors include not properly aspirated viscoelastic agent, using too small corneal grafts (under $7 \mathrm{~mm}$ ) or suturing corneal grafts too „tight” [14]. Long-lasting steroid therapy as well as presence of blood or fibrin in iridocorneal angle can lead to elevated IOP postoperatively.

Increased IOP depends on type of keratoplasty and its indication. It occurs most often (60\%) after PKP and DSEK [15], whereas considerably rarely after Descemet's membrane endothelial keratoplasty (DMEK) (6,5\%) [16]. Penetrating keratoplasties „à chaud” in keratitis or corneal perforation also carry a higher risk of elevated IOP [17].

Glaucoma neuropathy after keratoplasty is diagnosed mostly in the first postoperative months [17]. The lack of early diagnosis of glaucoma is due to inaccurate tonometry as a result of changed pachymetry measures and corneal biomechanics. It is suggested that precise pachymetry relied on spectroscopic optical coherence tomography (AS-OCT) scans can be useful in determining an increase in ocular pressure. On the other hand, decreasing pachymetry measures after keratoplasty can be an early sign of constantly elevated IOP [18]. Other glaucoma diagnostic methods may not be accurate because of reduced transparency of the optic media, high astigmatism or narrow pupil. Moreover, ultrabiomicroscopy results are variable as the effect of eyeball deformation after applied pressure or imprecise eyeball position during examination $[19,20]$. Nowadays, analysing anterior segment of the eye using non-contact optical co- herence tomography (OCT) seems to be a reliable method of iridocorneal angle and corneal thickness assessment in patients after keratoplasty.

The paper presents mechanisms of increased IOP during early period after keratoplasty, based on clinical evaluation of the eye morphometry as well as literature review.

There are three types of morphometrical changes observed within the anterior segment of the eye that seem to be a reason of increased IOP after keratoplasty, e.g. narrowing of the iridocorneal angle, presence of peripheral anterior synechiae and presence of pupillary block.

\section{NARROWING OF THE IRIDOCORNEAL ANGLE AS A CAUSE OF INCREASED INTRAOCULAR PRESSURE AFTER KERATOPLASTY}

There are some factors that influence postoperative width of the iridocorneal angle, e.g. diameter of the recipient's cornea, size of the corneal graft and graft suturing method [13]. Based on the AS-OCT imaging the following parameters can be measured to assess important morphometrical changes after keratoplasty: AOD500 (angle opening distance) - which is a distance between cornea and iris perpendicular to the cornea $500 \mu \mathrm{m}$ from the scleral spur, TISA500 (trabecular iris space area) - trapezoidal area between cornea and iris $500 \mu \mathrm{m}$ from the scleral spur into the anterior chamber and SSA (scleral spur angle) - representing iridocorneal angle width starting in the scleral spur [21].

\section{Case reports}

\section{Case 1.}

Penetrating keratoplasty combined with cataract surgery and IOL implantation in patient with bullous keratopathy, pachymetry $>1000 \mu \mathrm{m}$ and mature cataract (fig. 1A). Before surgery iridocorneal angle was $41^{\circ}$ wide in the OCT scans (fig. 1B). In the early postoperative period, correctly sutured corneal graft and narrowed iridocorneal angle $\left(38^{\circ}\right)$ was found (fig. 1C, 1D). There was no other potential cause of elevated IOP. 


\section{FIGURE ( 1}

Bullous keratopathy and mature cataract. A. Preoperative biomicroscopic image. B. Preoperative AS-OCT scan.

C. Biomicroscopic image after penetrating keratoplasty. D. AS-OCT scan: narrowing of the iridocorneal angle.
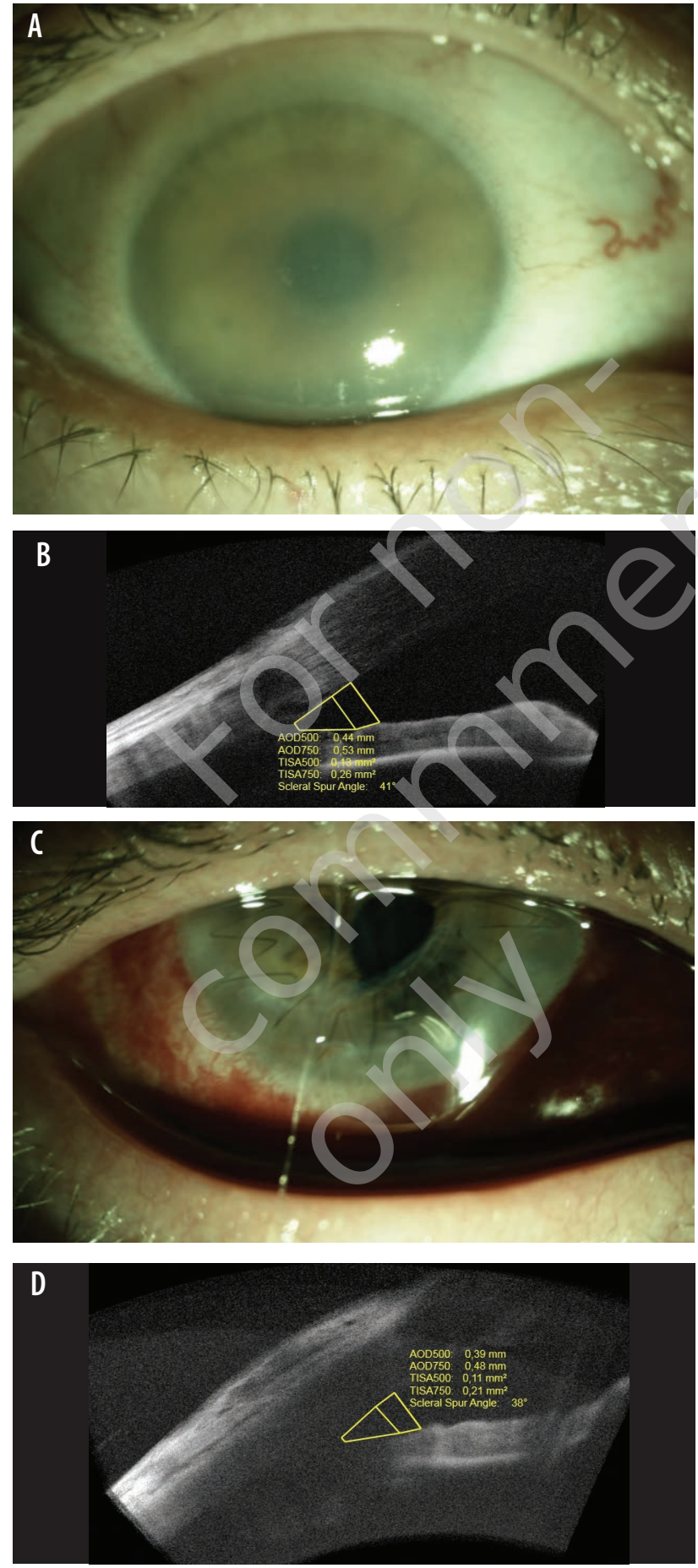

Case 2.

A patient with ocular pain and reduced visual acuity due to Fuchs' corneal dystrophy (fig. 2A). Two days after endothelial keratoplasty (fig. 2B) elevated IOP $\geq 30 \mathrm{mmHg}$ was observed. In AS-OCT narrowing of the iridocorneal angle from $54^{\circ}$ preoperatively (fig. $2 \mathrm{C}$ ) to $42^{\circ}$ postoperatively was found. Additionally, bulging of the central and peripheral iris as well as air bubble in the anterior chamber were still present (fig. 2D).

\section{FIGURE ( 2}

Fuchs' corneal dystrophy, A. Preoperative biomicroscopic image. B. Biomicroscopic image after lamellar keratoplasty.

C. Preoperative AS-OCT scan. D. AS-OCT scan: narrowing of the iridocorneal angle.
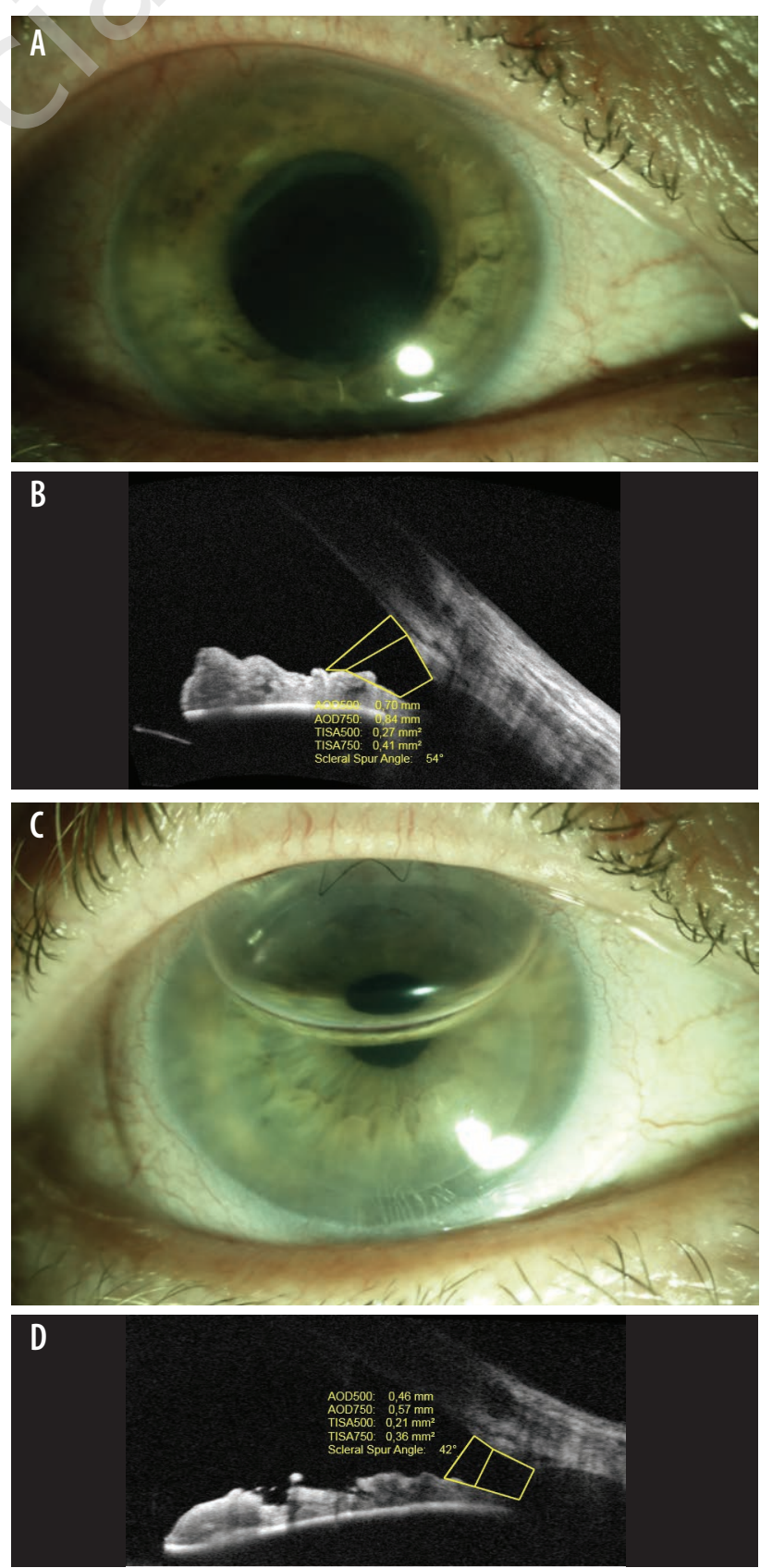


\section{Case 3.}

A patient suffering from central corneal scarring and significantly reduced visual acuity, who underwent PKP with $8 \mathrm{~mm}$ corneal graft. During first postoperative weeks an increased IOP > $30 \mathrm{mmHg}$ and narrow iridocorneal angle were observed (fig. 3A). Applied laser irydotomy widened iridocorneal angle sufficiently (fig. 3B), however the IOP stayed unchanged. Finally, a non-penetrating deep sclerectomy was performed (fig. $3 \mathrm{C}$ ), which resulted in lowering the IOP to $19 \mathrm{mmHg}$ without additional drug treatment.

\section{FIGURE 3}

Post-penetrating keratoplasty image. A. AS-OCT scan: narrow iridocorneal angle. B. AS-OCT scan: iridocorneal angle widening after laser iridotomy. C. Biomicroscopic image after non-penetrating deep sclerectomy.
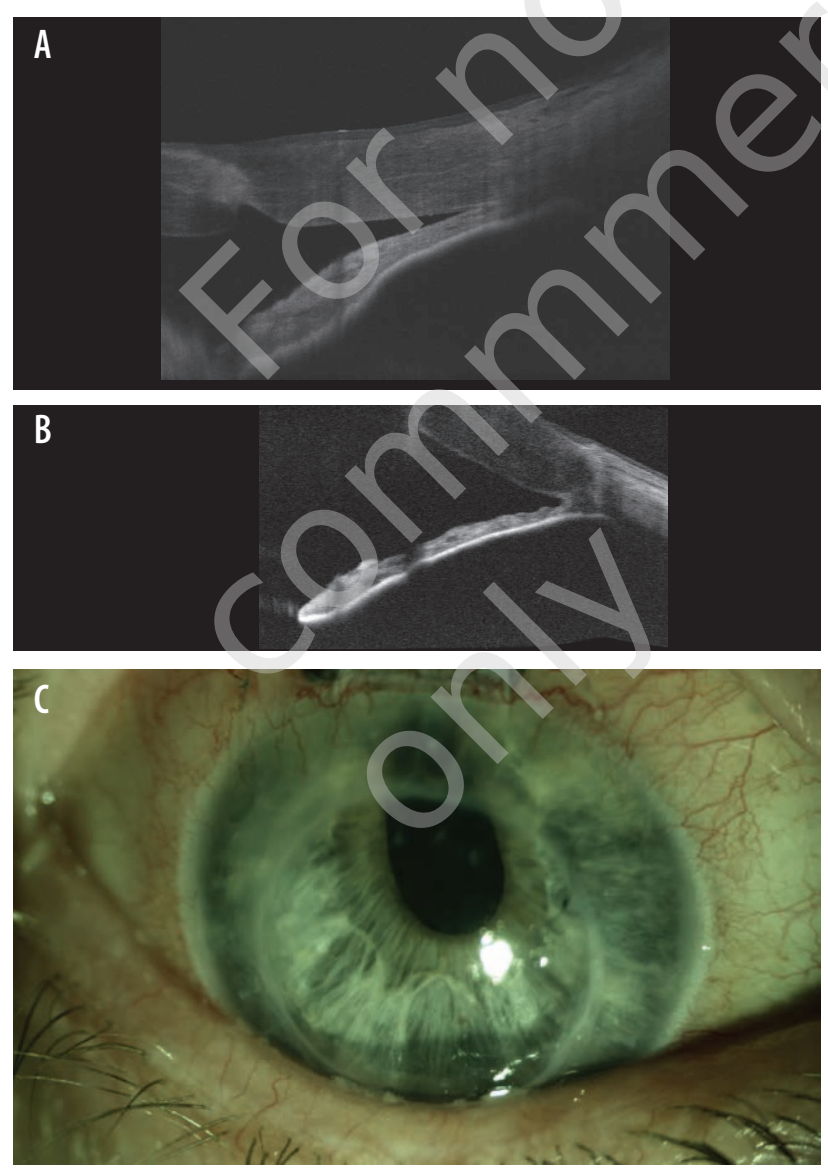

Treatment of the increased IOP associated with iridocorneal angle narrowing after keratoplasty commonly includes anti-glaucoma eyedrops combined with miotics. This conservative treatment can be also supplemented with laser procedures, that can be an effective option, as it has been shown in the first case - using peripheral iridoplasty or in the second case, in which laser iridotomy was performed. Successful lowering of the IOP with the use of laser treatment proves that its mechanism is strongly associated with the narrowing of the iridocorneal angle after keratoplasty. Nevertheless, due to reduced transparency of the optic media or suture-related corneal deformations after keratoplasty, laser procedures may be technically difficult in early postoperative period. Another therapeutic option to lower the elevated IOP are MIGS or non-penetrating deep sclerectomy in case of relatively wide iridocorneal angle (as it is has been presented in the third case) or trabeculectomy and glaucoma valve tube implantation in other cases.

\section{Anterior synechiae as a cause of increased intraocular pressure after keratoplasty}

Among numerous morphological changes of the iridocorneal angle, anterior synechiae seem to play an important role in pathomechanism of increased IOP after keratoplasty. They can be present in the anterior chamber before the surgery or appear as a consequence of postoperative complication [22]. It is suggested that anterior synechiae observed preoperatively should be treated as a routine surgical step. It has been proved that synechiolysis itself, the use of corneal graft $1 \mathrm{~mm}$ bigger then trephinated recipient's cornea, filling the anterior chamber with viscoelastic substance during surgery or performing oculopression before surgery can effectively reduce synechiae. Moreover, the use of steroid drops after keratoplasty reduces inflammatory response and efficiently prevents formation of anterior synechiae in early postoperative period [23].

\section{Case reports}

\section{Case 1.}

A patient 2 years after previously performed penetrating keratoplasty due to acute corneal hydrops complications. In the follow-up constantly elevated IOP $\geq 25 \mathrm{mmHg}$ as well as intumescent cataract were observed (fig. 4A). OCT scans revealed presence of peripheral anterior synechiae in the huge area (fig. 4B). The patient was qualified to cataract surgery and IOL implantation combined with intraoperative mechanical synechiolysis (fig. 4C). The procedure resulted in significant widening of the iridocorneal angle, change of iris shape (fig. 4D) and gradual drop in IOP. Eventually the level of IOP of $18 \mathrm{mmHg}$ was achieved that enabled withdrawing anti-glaucoma drugs. 


\section{FIGURE 4}

Post-penetrating keratoplasty image. A. Biomicroscopic image 2 years after keratoplasty. B. AS-OCT scan: anterior synechiae.

C. Biomicroscopic image after cataract surgery with synechiolysis. D. Postoperative AS-OCT scan.
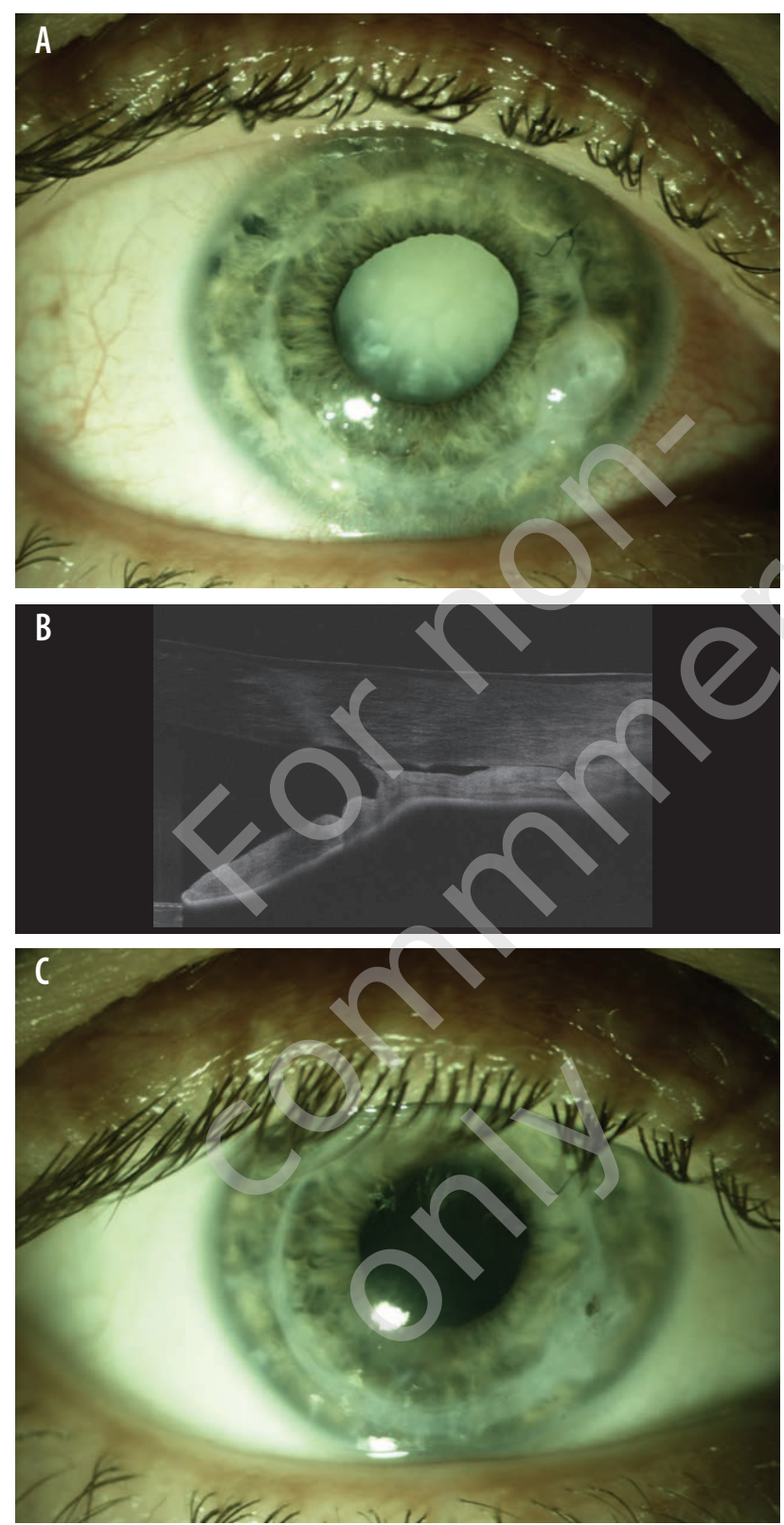

D
Case 2.

A patient with diagnosed rheumatoid arthritis and glaucoma, who underwent PKP due to corneal perforation. One-year follow-up observation showed thinning of the corneal graft, descemetocele, shallowing of the anterior chamber, anterior synechiae formation and rise in IOP $\geq 25 \mathrm{mmHg}$ (fig. 5A, B). Decision of repeated PKP combined with synechiolysis was made, which resulted in significant widening of the iridocorneal angle and consequently gradual decrease in the IOP to $15 \mathrm{mmHg}$ (fig. 5C, D).

Pharmacological synechiolysis including mydriatics or miotics as well as oculopression is an advisable method before keratoplasty in some cases. When the surgery is finally planned it should be completed with intraoperative synechiolysis.

\section{PUPILLARY BLOCK AS A CAUSE OF INCREASED INTRAOCULAR PRESSURE AFTER KERATOPLASTY}

Pupillary block is commonly observed as a consequence of graft air tamponade after DSEK/DMEK [24]. Depending on location and volume, air bubble can induce: anterior pupillary block (when located in the anterior chamber and pushing iris backwards) or posterior pupillary block (when the air is dislocated behind the iris, pushing the iris anteriorly making peripheral iridocorneal adhesion and closing the iridocorneal angle).

\section{FIGURE $(5$}

Post-penetrating keratoplasty image. A. Biomicroscopic image 1 year after keratoplasty. B. AS-OCT scan: descemetocele, anterior synechiae. C. Biomicroscopic image after re-keratoplasty with synechiolysis. D. Postoperative AS-OCT scan.

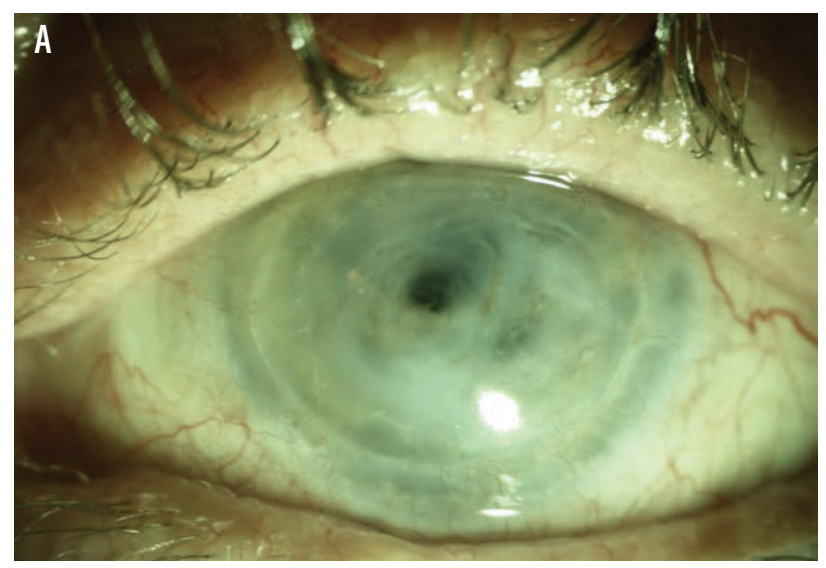



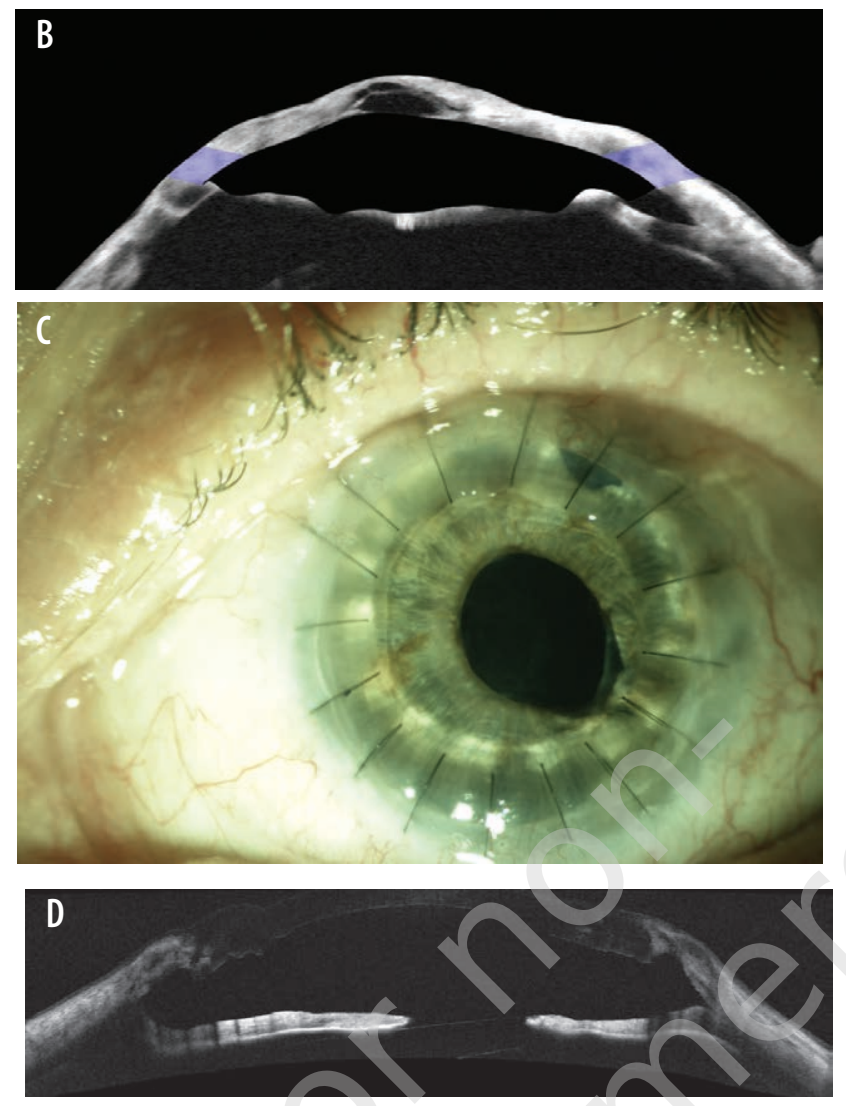

\section{Case reports}

Case 1.

A patient after DSEK combined with cataract surgery and IOL implantation due to bullous keratopathy associated with Fuchs' corneal dystrophy. Postoperatively a significant increase in IOP $>40 \mathrm{mmHg}$ was observed and did not normalize after anti-glaucoma drops and intravenous osmotic agents. Slit lamp and OCT examination revealed air bubble located behind the iris, leading to iris bombe and posterior pupillary block (fig. 6A, B). Taking all these information into account, the patient was qualified to YAG-iridotomy, which resulted in iris flattening and fast lowering of the IOP $<20 \mathrm{mmHg}$. Interestingly, the procedure did not relocate the air bubble to the anterior chamber.

\section{FIGURE 6}

Post-lamellar keratoplasty image. A, B. AS-OCT scan and biomicroscopic image: posterior pupillary block.
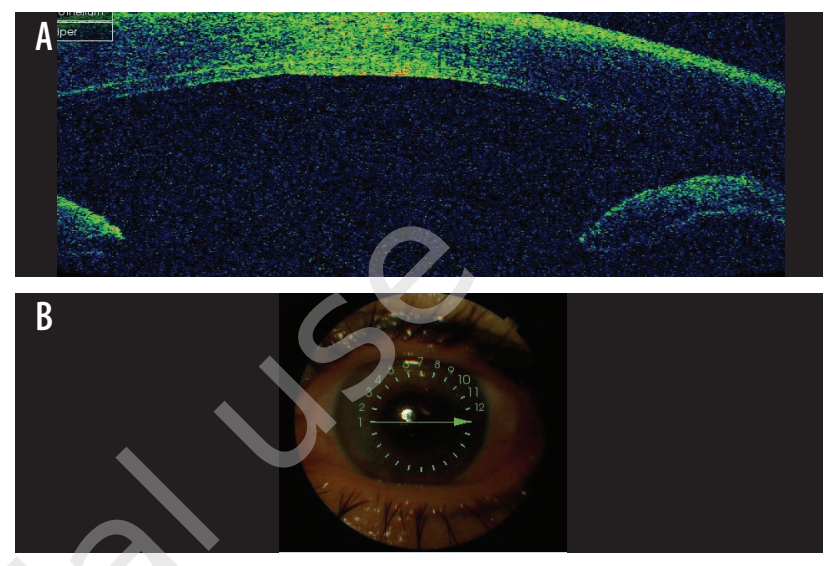

\section{Case 2.}

A patient, who underwent endothelial keratoplasty with basal iridectomy due to corneal edema (fig. 7A, B). Directly postoperatively elevated IOP $>35 \mathrm{mmHg}$ was observed. Biomicroscopy and OCT scans presented a "mixed" type of pupillary block, in which one air bubble deepened the upper half of the anterior chamber leading to iridolenticular adhesion and anterior pupillary block (fig. 7C). Whereas the second air bubble dislocated behind the iris moved lower part of the iris anteriorly inducing posterior pupillary block (fig. 7D). Because YAG-iridotomy was not effective, the treatment included anti-glaucoma eye drops, mydriatics and intravenous osmotic agents for the next 2 days. Finally, spontaneous decrease in air bubble volume together with its relocation into the anterior chamber led to breaking the posterior pupillary block improving the iridocorneal angle anatomy and eventually lowering IOP $<20 \mathrm{mmHg}$. 


\section{FIGURE 7}

Post-lamellar keratoplasty image. A, B. Postoperative biomicroscopic image. C. AS-OCT scan: anterior pupillary block. D. AS-OCT scan: posterior pupillary block.
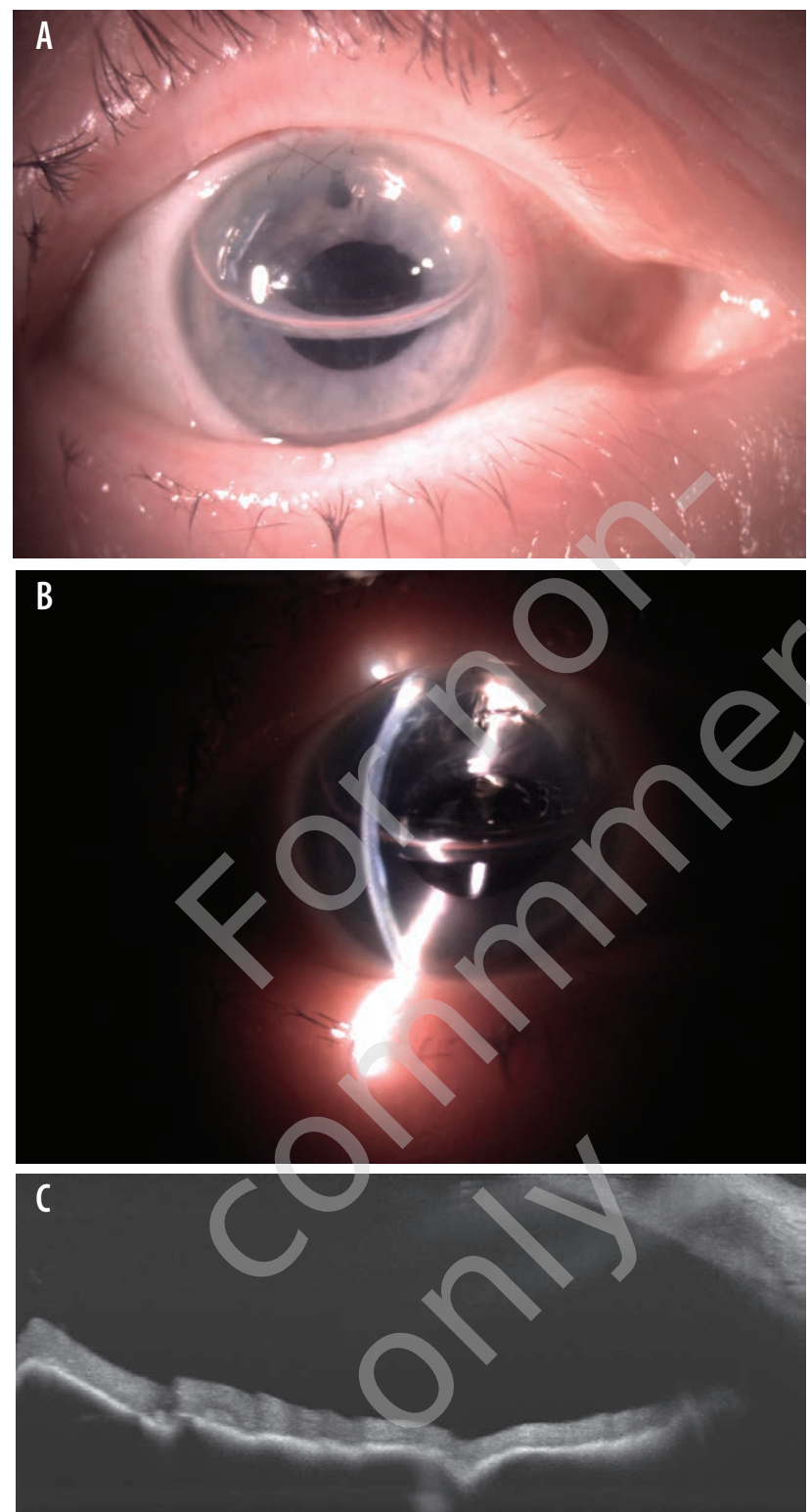

D

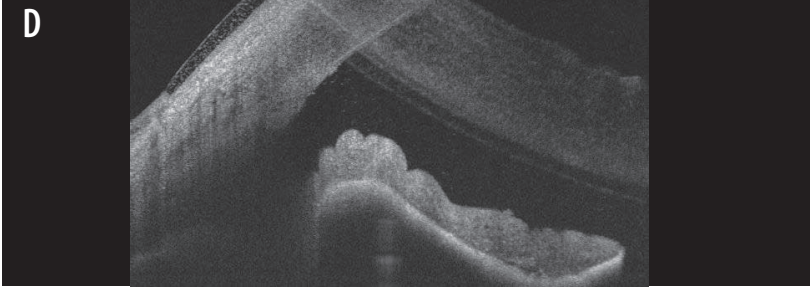

It is worth mentioning, that DSEK/DMEK procedure requires iridotomy that should be performed preoperatively using NdYAG/argon laser on intraoperatively with scissors excision. It is well known that postoperative iridotomy is difficult to perform, as it has been shown in our cases. Other possible option is anterior chamber punction with aspiration of some air volume, which can be a risky manouver for corneal graft adhesion or anterior chamber stability.

\section{OTHER CAUSES OF INCREASED INTRAOCULAR PRESSURE AFTER KERATOPLASTY}

While the iridocorneal angle seems to be normal, the mechanism of elevated IOP after keratoplasty may be not so well defined. A meticulous examination of patient's medical history is necessary to find any sign of glaucomatous neuropathy, method of previous treatment (conservative or surgical) or long lasting steroid therapy.

\section{Case report}

A patient after endothelial (DSEK) surgery due to corneal edema associated with Fuchs' corneal dystrophy (fig. 8A). Postoperatively a significant increase in IOP $>30 \mathrm{mmHg}$ was observed. Iridocorneal angle in gonioscopy and on OCT scans was wide and open (fig. 8B, C). However, patient's history revealed long-term drug therapy of glaucoma with two medications. Reintroducing of previously used drugs did not normalize IOP and glaucoma progression was observed. A non-penetrating deep sclerectomy was performed (fig. 8D, E), which finally resulted in decrease in $\mathrm{IOP}<20 \mathrm{mmHg}$ preventing further glaucoma progression.

\section{FIGURE $(8$}

Post-lamellar keratoplasty image. A. Postoperative biomicroscopic image. B, C. Gonioscopic image and AS-OCT scan: open iridocorneal angle. D. Biomicroscopic image after non-penetrating deep sclerectomy. E. Postoperative gonioscopic image.

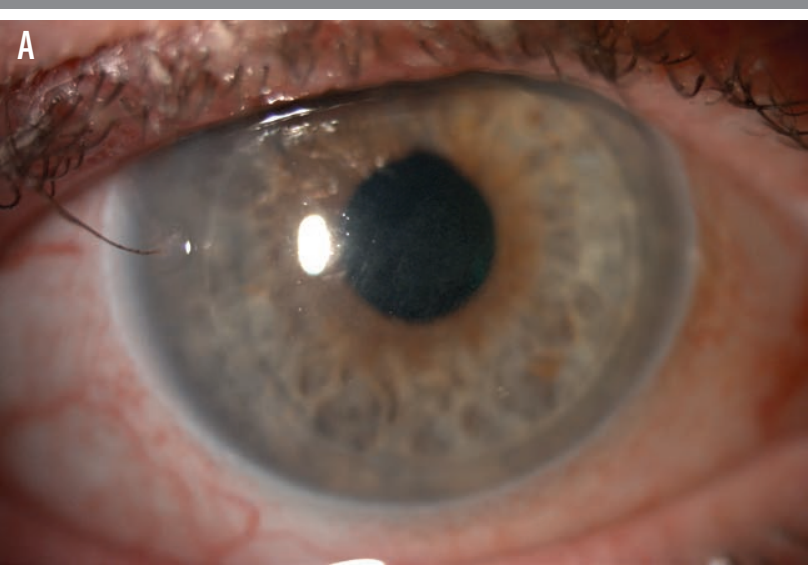



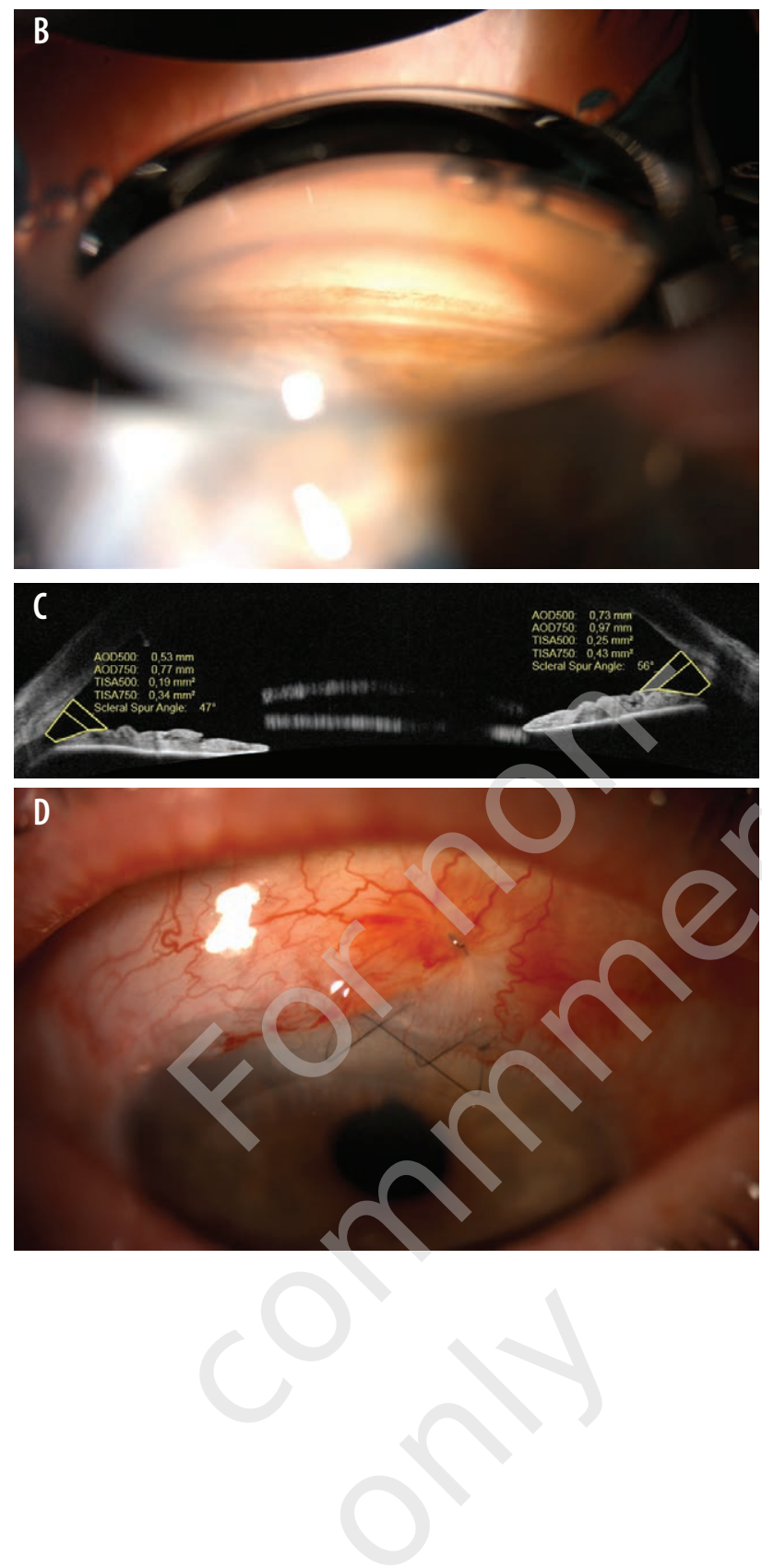

\section{CORRESPONDENCE}

\section{Diana Wyroślak-Bednarek, MD}

Department of Ophthalmology and Vision Rehabilitation,

Medical University of Lodz

90-549 Lodz, ul. Żeromskiego 113

e-mail:dianawyroslak@yahoo.com
E

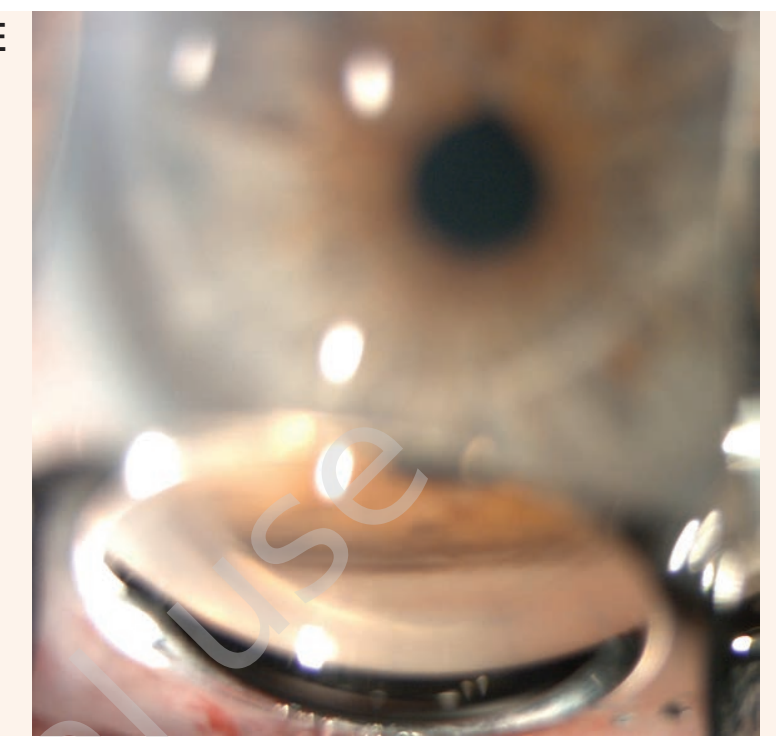

\section{CONCLUSIONS}

Keratoplasty is one of the most effective types of transplantation procedure with relatively good postoperative prognosis. Immunological graft rejection and increased IOP or glaucoma neuropathy are the most significant reasons of decreased visual functions and graft lost. Pathomechanism of elevated IOP is complex and includes pre-, intraand postoperative factors. Moreover, the assessment of increased IOP in eyes after keratoplasty is burdened with error, mainly due to changed corneal biomechanics leading to inaccurate IOP measurements. To find out potential cause of increased IOP, gonioscopy and OCT with iridocorneal angle assessment are crucial, revealing deformation of peripheral cornea with narrowing of the iridocorneal angle, presence of anterior synechiae and pupillary block. It is worth mentioning that an increase in IOP is possible independently of above mentioned factors, therefore long-term observation after keratoplasty is recommended.

Figures: from the author's own materials.

\section{ORCID}

Piotr Jurowski - ID - http://orcid.org/0000-0003-1471-8577

Diana Wyroślak-Bednarek - ID - http://orcid.org/0000-0001-5561-2811

Zofia Pniakowska - ID - http://orcid.org/0000-0003-0144-4394 


\section{References}

1. Zirm EK. Eine erfolgreiche totale Keratoplastik (A successful total keratoplasty). 1906. Refract Corneal Surg. 1989; 5(4): $258-61$.

2. Czerwiński J (ed). Biuletyn Informacyjny. Centrum Organizacyjno-Koordynacyjnego ds. Transplantacji Poltransplant. $2019: 45-6$.

3. Reinhard T, Kallmann C, Cepin A et al. The influence of glaucoma history on graft survival after penetrating keratoplasty. Graefes Arch Clin Exp Ophthalmol. 1997; 235(9): 553-7.

4. Irvine AR, Kaufman HE. Intraocular pressure following penetrating keratoplasty. Am J Ophthalmol. 1969; 68(5): 835-44.

5. Wilson SE, Kaufman HE. Graft failure after penetrating keratoplasty. Surv Ophthalmol. 1990; 34(5): 325-56.

6. Ayyala RS. Penetrating keratoplasty and glaucoma. Surv Ophthalmol. 2000; 45(2): 91-105.

7. Seitz B, Langenbucher A, Nguyen NX et al. Long-term follow-up of intraocular pressure after penetrating keratoplasty for keratoconus and Fuchs' dystrophy: comparison of mechanical and Excimer laser trephination. Cornea. 2002; 21(4):368-73.

8. Greenlee EC, Kwon YH. Graft failure. III. Glaucoma escalation after penetrating keratoplasty. Int Ophthalmol. 2008; 28(3): $191-207$.

9. Foulks GN. Glaucoma associated with penetrating keratoplasty. Ophthalmology. 1987; 94(7): 871-4.

10. Dada T, Aggarwal A, Minudath KB et al. Post-penetrating keratoplasty glaucoma. Indian J Ophthalmol. 2008; 56(4): $269-77$.

11. Vajaranant TS, Price MO, Price FW et al. Visual acuity and intraocular pressure after Descemet's stripping endothelial keratoplasty in eyes with and without preexisting glaucoma. Ophthalmology. 2009; 116(9): 1644-50.

12. Espana EM, Robertson ZM, Huang B. Intraocular pressure changes following Descemet's stripping with endothelial keratoplasty. Graefes Arch Clin Exp Ophthalmol. 2010; 248(2): 237-42.

13. Maier AKB, Klamann MKJ, Torun N et al. Intraocular pressure elevation and post-DSEK glaucoma after Descemet's stripping endothelial keratoplasty. Graefes Arch Clin Exp Ophthalmol. 2013; 251: 1191-8.

14. Olson RJ, Kaufman HE. A mathematical description of causative factors and prevention of elevated intraocular pressure after keratoplasty. Invest Ophthalmol Vis Sci. 1977; 16(12): 1085-92.

15. Anshu A, Price MO, Price FW Jr. Risk of corneal transplant rejection significantly reduced with Descemet's membrane endothelial keratoplasty. Ophthalmology. 2012; 119(3): 536-40.

16. Naveiras M, Dirisamer M, Parker J et al. Causes of glaucoma after Descemet membrane endothelial keratoplasty (DMEK). Am J Ophthalmol. 2012; 153(5): 958-66.

17. Yildirim N, Gursoy H, Sahin A et al. Glaucoma after Penetrating Keratoplasty: Incidence, Risk Factors, and Management. J Ophthalmol. 2011; 2011: 951294.

18. Al-Mahmood AM, Al-Swailem SA, Deebak PE. Glaucoma and Corneal Transplant Procedures. J Ophthalmol. 2012; 2012: 576394.

19. Tello C, Liebmann J, Potash SD et al. Measurement of ultrasound biomicroscopy images: intraobserver and interobserver reliability. Invest Ophthalmol Vis Sci. 1994; 35(9): 3549-52.

20. Urbak SF, Pedersen JK, Thorsen TT. Ultrasound biomicroscopy. II. Intraobserver and interobserver reproducibility of measurements. Acta Ophthalmol Scand. 1998; 76(5): 546-9.

21. Shi Y, Marion KM, Jenkins D et al. Identification and Characterization of Imaging Technique Errors and Artifacts Using Anterior-Segment OCT for Irido-Corneal Angle Evaluations in Glaucoma. Ophthalmol Glaucoma. 2019; 2(3): 136-44.

22. Maier AK, Gundlach E, Gonnermann J et al. Anterior segment analysis and intraocular pressure elevation after penetrating keratoplasty and posterior lamellar endothelial keratoplasty. Ophthalmic Res. 2015; 53(1): 36-47.

23. Zemba M, Stamate AC. Glaucoma after penetrating keratoplasty. Rom J Ophthalmol. 2017; 61(3): 159-65.

24. Sugar A, Tanner JP, Dontchev M et al. Recipient Risk Factors for Graft Failure in the Cornea Donor Study. Ophthalmology. 2009; 116(6): 1023-8. 


\section{Authors' contributions:}

Diana Wyroślak-Bednarek: 50\% - main idea of the manuscript, realization of the idea, translation of the manuscript;

Piotr Jurowski: 25\% - substantive consultation; Zofia Pniakowska: 25\% - acquire of the photograph.

\section{Conflict of interest:}

None.

\section{Financial support:}

None.

\section{Ethics:}

The content presented in the article complies with the principles of the Helsinki

Declaration, EU directives and harmonized requirements for biomedical journals.

(c) Medical Education. For private and non-commercial use only. Downloaded from https://www.journalsmededu.pl/index.php/ophthatherapy/index: 26.04.2023; 13:53,12 